\title{
The use of a new generation chemicals on early ripening potatoes
}

\author{
Ryslan Gish, Anastasiya Zvyagina*, and Nina Arakelyan \\ Kuban State Agrarian University, 13 Kalinina Str., Krasnodar, Russia
}

\begin{abstract}
To obtain high yields of potatoes, plant growth and development regulators of various origins are used. Recently, the use of chemicals made from natural raw materials has become more widespread. One of them is the chemicals Relict based on humic and fulvic acids, which have growth-stimulating adaptogenic and protective properties from peat. It is used both for treatment of tubers before planting, and for vegetative plants treatment. Such treatment allowed to reduce the sparseness in potato plantings, and also contributed to an increase in the yield of large and medium fractions of tubers. The marketability of tubers in the control is $81.7 \%$, and in the areas treated with Relict is higher - at a concentration of $0.01 \%-91.6 \%$, and by $0.05 \%-93.7 \%$.
\end{abstract}

\section{Introduction}

Modern intensive agricultural production involves, on the one hand, obtaining the maximum yield of the cultivated crop with minimal costs, on the other-improving the quality of products. The use of humic fertilizers allows solving this problem comprehensively. The list of humic chemicals recommended for vegetable crops and potatoes is updated annually [1].

One of the natural regulators of plant growth and development is the humic chemicals Relict. Its principle of action is the natural stimulation of the plant body and the improvement of biological processes occurring in them. First of all, the chemical acts on cells, and then - on plant tissues, it activates bioenergetic processes, stimulates metabolism, improves the penetration of nutrients through the cell membrane, the work of the enzymatic system, increases the stress resistance of plants. The effectiveness of this chemicals increases in the period of sudden changes in weather conditions. It helps plants cope with the effects of frost, drought, and reduce chemical stress from pesticide treatment. As a nonspecific activator of the immune system, Relict increases the resistance of plants to various diseases.

In the course of research, it was revealed:

1. The chemicals Relict had a positive effect on the formation of the yield of tubers - an increase in the range of 9-11 is achieved \%;

2. There was an increase in the total marketability of tubers, at which the sum of two fractions (large and medium, i.e. $(60+30 \mathrm{~mm})$ when treated with the chemicals with a concentration of $0.01 \%-91.6 \%$, and by $0.05 \%-93.7 \%$.

\footnotetext{
*Corresponding author: yatsanmi@mail.ru
} 


\section{Problem Statement}

Potatoes in terms of their social significance and commercial attractiveness in Russia consistently ranks second after cereals. Effective agricultural production is impossible without development of intensive technologies that are designed for the use of pesticides that negatively affect plants, soil and environment as a whole. In this regard, the role of natural stimulators of the organism of cultivated plants is increasing and has recently been widely used by rising the stress resistance of plants (temperature changes, soil salinization, pesticide treatment, jumps in solar insolation).

The use of the new generation chemicals Relict can improve the productivity of photosynthesis, reduce the impact of stressful natural factors, as well as the toxic effect of herbicides on the crop [2].

\section{Research Questions}

\subsection{Research objects}

The object of the research was the Lisetta potato variety, bred in the Netherlands. It is a mid-early variety. Tubers are oblong-oval. The flesh is yellow. The variety is multituberous, high-yielding. It is resistant to late blight and nematode. It is moderately tolerant to scab.

\subsection{Research subject}

The subject of the research was the study of the effect of the chemicals Relict on yield and quality of potato tubers of the Lisetta potato variety. The experiments were carried out in the field crop rotation of LLC "Gogushev K. I." of Khabez district, Karachay-Cherkess Republic.

\section{Purpose of the Study}

The purpose of the work: to establish the agrotechnological effectiveness of the Relict use on early ripening potatoes.

The choice of the region is justified by the fact that Karachay-Cherkess Republic is a large region for the production of food potatoes in the North Caucasus. Here, in farms and sole proprietors, the main crop is potatoes, the cultivation technology of which is well mastered by them, which confirms the high yields in farms.

By conducting these studies, it was planned to identify the possibilities of the agrochemicals Relict in terms of increasing potato yield by selecting technological regulations for its use, in order to organize its mass use in the region in the future.

\section{Research Methods}

The predecessor of the potato was barley. The system of tillage is carried out according to the type of semi-fallow. After harvesting the predecessor, the soil was treated with disk tools and plowed to a depth of 27-30 cm. During the autumn period, the soil preparation is completed. In the farm "Gogushev I. K." part of the potatoes are planted on a profiled surface (ridges), which are formed in the fall. Part of the landings, including the experimental site, fell on a flat surface. 
Potato planting material was imported from the central part of Russia, buying from farmers engaged in the cultivation of seed tubers. The planting material in the experiment was prepared as follows: sorting was carried out, the tubers were divided by weight into 2 groups (25-30 $\mathrm{g}$ and 35-40 g). In the experiment, the second group of tubers was used. Planting was carried out in the third decade of March, at a soil temperature of $+5 . . .+8^{\circ} \mathrm{C}$. The landing rate of planting material is $2.7 \mathrm{t} / \mathrm{ha}$, the planting depth is $10-12 \mathrm{~cm}$, the planting method is ordinary, with a row spacing of $70 \mathrm{~cm}$ and a distance between tubers in a row of $30 \mathrm{~cm}$. When planting, a nitroammophosk of $5 \mathrm{c} /$ ha was introduced. Care works are the following:

- spring harrowing in mid-April;

- at a plant height of 10-15 cm, the first soil loosening was carried out, followed by 10 -

15 days with an increase in the depth processing and simultaneous hoeing.

The plant protection system included treatment with Fundazol (300 g/ha), Abiga-Pik (3 $\mathrm{kg} / \mathrm{ha}$ ), and Biskay insecticide (200 g/ha); the second treatment was carried out in the first decade of June, and Ridomil Gold (2.5 kg/ha) was used against fungal diseases. At the end of June, potato plantings were sprayed with Infinito against fungal diseases (1.4 l / ha); Konfidor was used against the Colorado potato beetle [3].

Potato tubers were harvested in biological ripeness. Before harvesting, the tops were mowed in the field, the plants were dugged up with the KST-1,4 machine-digger. The tubers were selected manually, with subsequent sorting and packing.

\section{Results}

In order to identify the effect of Relict on the passage of phenological phases, the timing of their occurrence and the reasons that determine these terms, observations were included in the experiment, the results of which are shown in Table 1.

Treatment of tubers with the chemicals helped to accelerate the mass regrowth of stems for 2-4 days. This intensity of growth processes persisted until the "mass budding" phase. By the end of the mass flowering phase, the effect of the chemicals weakened and the difference in the onset of the phase was reduced to 1-2 days.

Table 1. The effect of Relict on the passage of phenological phases in potato plants of the Lisetta potato variety (Farm "Gogushev K. I.", Khabez district, Karachay-Cherkess Republic, 2020.)

\begin{tabular}{|c|c|c|c|c|c|c|c|}
\hline \multirow{2}{*}{ Type } & \multicolumn{5}{|c|}{ Phenological phase } & \multirow{2}{*}{ Harvest } \\
\cline { 2 - 7 } & \multicolumn{2}{|c|}{ regrowth } & \multicolumn{2}{c|}{ budding } & \multicolumn{2}{c|}{ flowering } & \\
\cline { 2 - 7 } & beginning & mass & beginning & mass & beginning & mass & \\
\hline Control & 18.04 & 26.04 & 18.05 & 20.05 & 26.05 & 28.05 & 21.08 \\
\hline Relict, 0,01\% & 16.04 & 24.04 & 16.05 & 18.05 & 24.05 & 27.05 & 19.08 \\
\hline Relict, 0,05\% & 16.04 & 22.04 & 17.05 & 19.05 & 24.05 & 26.05 & 19.08 \\
\hline
\end{tabular}

The chemicals had an effect on the height of potato plants and leaf apparatus (Table 2). In the flowering phase, the highest height was reached by plants treated with a solution at a concentration of $0.05 \%$, which exceeded the control by $11 \mathrm{~cm}$, and at a lower concentration by $8 \mathrm{~cm}$.

Table 2. Effect of plant treatment with Relict agrochemicals on biometric parameters of the aboveground part of potatoes (farm "Gogushev K. I.", Khabez district, Karachay-Cherkess Republic, 2020

\begin{tabular}{|c|c|c|}
\hline Type & Plant height, cm & Number of leaves, pcs \\
\hline Control & 42 & 32 \\
\hline Relict, $0,01 \%$ & 50 & 36 \\
\hline Relict, $0,05 \%$ & 53 & 36 \\
\hline
\end{tabular}


Both concentrations of the chemicals used affected the number of leaves on the plants. At the same time, the effect of the chemicals in increasing the number of leaves was the same and exceeded the control by an average of 4 leaves.

The number of leaves in potato plants and their size determine the area of the assimilation surface. It had differences in the cross-section of variants and was in the range of $770-810 \mathrm{~cm}^{2}$, when treated with a concentration of $0.01 \%$ and $0.05 \%$, respectively. Note that the area of the leaf surface of potato plants is an important factor in the formation of the tuber crop, but not the only one: the intensity of the photosynthesis process, due to the quantitative and qualitative composition of pigments, environmental conditions, primarily temperature and light factors, varietal characteristics, are no less important components in the formation of the tuber crop.

In our studies, the positive effect of the chemicals was most pronounced in the variant with pre-planting treatment of tubers and with double foliar treatment at a concentration of $0.05 \%$ (Table 3).

The positive effect of the chemicals on reducing sparseness in plantings was also noted. Potato plants in the areas treated with Relict at a concentration of $0.05 \%$ had the least sparseness (6.1\%) compared to $11.3 \%$ in the control.

Table 3. Effect of Relict concentration on potato yield (Farm "Gogushev K. I.", Khabez district, Karachay-Cherkess Republic, 2020.)

\begin{tabular}{|c|c|c|c|c|}
\hline \multirow[t]{3}{*}{ Type } & \multicolumn{4}{|c|}{ Parameter } \\
\hline & \multirow{2}{*}{$\begin{array}{l}\text { plant standing } \\
\text { density, th. pcs/ha }\end{array}$} & \multirow{2}{*}{$\begin{array}{l}\text { sparseness in } \\
\text { plantings, \% }\end{array}$} & \multicolumn{2}{|r|}{ Yield } \\
\hline & & & t/ha & $\%$ to concentration \\
\hline Control & 42,2 & 11,3 & 31,7 & 100 \\
\hline Relict, $0,01 \%+2$ treatments & 43,1 & 9,5 & 34,5 & 109 \\
\hline Relict, $0,05 \%+2$ treatments & 44,7 & 6,1 & 35,1 & 111 \\
\hline $\mathrm{HCP}$ & & & 2,4 & \\
\hline
\end{tabular}

Solutions of the chemicals with concentrations of $0.01 \%$ and $0.05 \%$ contributed to an increase in yield by 9 and 11\%, respectively. The marketability of tubers was high in all variants. In the control group, it was $87.4 \%$, and in the areas with plants treated with agrochemicals, it was slightly higher: when treated with a concentration of $0,01 \%-91,6$ $\%, 0,05 \%-93,7 \%$. We believe that this trait depends more on the genetic nature of the variety.

The agrochemicals Relict also had a positive effect on the structure of the potato crop (Table 4).

Table 4. Effect of foliar treatment of potatoes with the agrochemicals Relict on the fractional yield of tubers (farm "Gogushev K. I.", Khabez district, Karachay-Cherkess Republic, 2020)

\begin{tabular}{|c|c|c|c|}
\hline \multirow{2}{*}{ Variety } & \multicolumn{3}{|c|}{ Amount of tubers, \% of total amount } \\
\cline { 2 - 4 } & large & medium & small \\
\hline Ryabinushka & 45,3 & 36,4 & 18,3 \\
\hline Bonni & 48,6 & 32,7 & 18,7 \\
\hline Lisetta & 51,2 & 36,4 & 12,4 \\
\hline
\end{tabular}

The economic value is represented by tubers of two fractions - large and medium. The largest number of such fractions in the crop was observed among tubers obtained during processing with a concentration of $0.05 \%$ (87.6 \%). In the control group and in those treated with a $0.01 \%$ solution, the marketability was almost the same and amounted to $81.7 \%$ versus $81.3 \%$, respectively. 


\section{Conclusion}

Pre-planting treatment of potato tubers of the Lisetta potato variety with Relict at a concentration of $0.01 \%$, followed by two-time foliar additional fertilizing with a solution of $0.05 \%$ concentration, contributed to an increase in the yield of tubers by $11 \%$, against $9 \%$ at a concentration of $0.01 \%$ (tubers + double leaf additional fertilizing).

The chemicals did not have a significant effect on the passage of phenological phases of development and the reduction of the period of planting tubers - harvesting.

The use of this chemicals contributed to the yield of tubers of medium and large fractions by 5-6 \% (30 + $60 \mathrm{~mm})$, compared with the control.

\section{References}

1. N. Tymchik, E. Blagorodova, A. Zvyagina, In the collection: Vegetable growing from theory to practice Status of potato sector in Krasnodar region.. 259 (2019)

2. E. Dako, K. Jankowskiab M. Gnimassoua, Journal home page for Heliyon. Study of inhibition of germination of potato by ethylene. 72 (2020)

3. Yean-Uk Kim, Byun-Woo Lee Science of The Total Environment Earlier planting offsets the adverse effect of global warming on spring potato in South Korea 742 (2020) 